\title{
Organocatalysis with endogenous compounds: Towards novel non-enzymatic reactions
}

\author{
David G. Alberg a,b, Thomas B. Poulsen a , Søren Bertelsen ${ }^{a}$, Kasper L. Christensen ${ }^{\mathrm{a}, \mathrm{c}}$, Rune D. Birkler ${ }^{\mathrm{c}}$, \\ Mogens Johannsen ${ }^{c, *}$, Karl Anker Jørgensen ${ }^{\mathrm{a}, *}$ \\ ${ }^{a}$ Center for Catalysis, Department of Chemistry, Aarhus University, DK-8000 Aarhus C, DK, Denmark \\ ${ }^{\mathrm{b}}$ Department of Chemistry, Carleton College, Northfield, MN 55057, USA \\ ${ }^{\mathrm{c}}$ Department of Forensic Medicine, Section for Toxicology and Drug Analysis, Aarhus University, DK-8200 Aarhus N, DK, Denmark
}

\section{A R T I C L E I N F O}

\section{Article history:}

Received 16 February 2009

Revised 20 March 2009

Accepted 25 March 2009

Available online 28 March 2009

\section{Keywords:}

Organocatalysis

Aldol

Non-enzymatic

Acetone

Methylglyoxal

\begin{abstract}
A B S T R A C T
The aldol reaction of the endogeneous compounds acetone and methylglyoxal has been studied using organocatalysis in relation to biologically relevant non-enzymatic reactions. Under preparative conditions, 3-hydroxy-2,5-hexadione, known as Henze's ketol, is formed in high yield and with enantioselectivities up to $88 \%$ ee. Furthermore, Henze's ketol is also formed under simulated physiological conditions at micromolar scale, indicating that this reaction might take place in living organisms.
\end{abstract}

(c) 2009 Elsevier Ltd. All rights reserved.
Organocatalysis has recently proven highly efficient in the stereoselective synthesis of a large number of $\alpha$-substituted carbonyl compounds. ${ }^{1}$ The rediscovery of the organocatalytic aldol reaction in 2000 by List, Lerner and Barbas ushered in a new field in organic synthesis, ${ }^{2}$ and research in organocatalysis has since expanded exponentially. Inspired by the aldolase enzymes, the organocatalytic aldol reaction employs aminocatalysis for the activation of carbonyl compounds (aldol donors) by the formation of transient enamine species. The utility of the stereoselective organocatalytic aldol reaction has also been demonstrated in a number of total syntheses ${ }^{3}$ and the mechanism has been thoroughly studied by computational methods. ${ }^{4}$

Acknowledging that organocatalytic aldol reactions have been reported to proceed in aqueous environments, mediated by simple amino acid derivatives and peptides ${ }^{1,5}$ led us to believe that these reactions might occur in vivo. ${ }^{6}$ Intrigued by this possibility, we initiated a study to address the potential role of non-enzymatic organocatalytic reactions in human biochemistry. As model substrates, the endogenous compounds methylglyoxal $\mathbf{1}$ (pyruvaldehyde) and acetone $\mathbf{2}$ were chosen for our initial experiments.

Methylglyoxal $\mathbf{1}$ is a reactive endogenous $\alpha$-oxoaldehyde that is known to modify biomolecules in vivo through non-enzymatic

\footnotetext{
* Corresponding authors.

E-mail addresses: mj@forensic.au.dk (M. Johannsen), kaj@chem.au.dk (K.A. Jørgensen).
}

processes. ${ }^{7}$ The development of complications in relation to diabetes, as well as the general aging phenomenon, has been linked to protein modifications by $\mathbf{1}$. Although the concentration of 'free' $\mathbf{1}$ in vivo is in the high $\mathrm{nM}$ or low $\mu \mathrm{M}$ regime, the bulk of $\mathbf{1}$ is bound reversibly to nucleophilic groups present in biopolymers and to reduced glutathione. ${ }^{8}$ The total amount of $\mathbf{1}$ in biological systems may therefore be significant; for example, up to $310 \mu \mathrm{M}$ of $\mathbf{1}$ in cultured $\mathrm{CHO}$-cells ${ }^{9}$ has been measured and even concentrations in the $\mathrm{mM}$ range have been reported in the gingival fluid from periodontitis patients. $^{10}$

Acetone $\mathbf{2}$ belongs to the class of ketone bodies that are present in elevated (millimolar) levels during prolonged starvation or poorly controlled diabetes. ${ }^{11}$ To the best of our knowledge, the organocatalytic aldol reaction between $\mathbf{1}$ and $\mathbf{2}$ has not previously been studied. The product of this reaction, 3-hydroxy-2,5-hexadione 3, also known as Henze's ketol, ${ }^{12}$ bears an interesting history. The chemistry and biochemistry of $\mathbf{3}$ was extensively studied by Henze and his colleagues in the 1930s, and they went so far as to speculate that $\mathbf{3}$ might represent an undiscovered link between the metabolism of fatty acids and carbohydrates. This proposal was later disproved by Krebs, ${ }^{13}$ and no clear biological role for $\mathbf{3}$ has since emerged; however, this ketol has recently been identified in plant extracts. ${ }^{14}$ In the present work we report the enantioselective organocatalytic preparation of $\mathbf{3}$ on a synthetic scale, as well as its organocatalytic formation under simulated physiological conditions, at levels that may be biologically significant. 
Table 1

Screening of catalysts for organocatalytic formation of Henze's Ketol $\mathbf{3}$ from acetone and methylglyoxal ${ }^{\mathrm{a}}$<smiles>CC(=O)C1CCCN1</smiles>

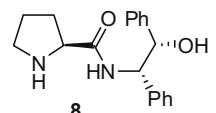<smiles>CC(=O)C=O</smiles>
Catalyst
$(20 \mathrm{~mol} \%)$<smiles>CO[As](C)O[Mg]</smiles><smiles>CC(=O)CC(O)C(C)=O</smiles><smiles>NC(=O)C1CCCN1</smiles>

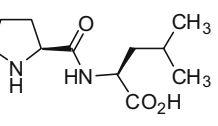

6
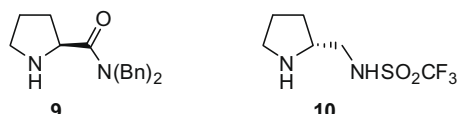

9

\begin{tabular}{lllll}
\hline Entry & Catalyst & Solvent & Yield (\%) & ee $^{\text {b }} \%$ \\
\hline $\mathbf{1}$ & $\mathbf{4}$ & Neat & $<5$ & nd \\
$\mathbf{2}$ & $\mathbf{4}$ & DMSO & $<10$ & 51 \\
$\mathbf{3}$ & $\mathbf{4}$ & $\mathrm{H}_{2} \mathrm{O}$ & $<5$ & nd \\
$\mathbf{4}$ & $\mathbf{5}$ & Neat & 76 & 65 \\
$\mathbf{5}$ & $\mathbf{6}$ & Neat & $<5$ & 33 \\
$\mathbf{6}^{\text {c }}$ & $\mathbf{7}$ & Neat & 55 & 88 \\
$\mathbf{7}$ & $\mathbf{8}$ & Neat & 81 & 62 \\
$\mathbf{8}$ & $\mathbf{9}$ & Neat & 52 & 0 \\
$\mathbf{9}$ & $\mathbf{1 0}$ & Neat & 39 & -66 \\
\hline
\end{tabular}

a Standard conditions: To a stirred solution of the catalyst $(0.05 \mathrm{mmol})$ in the specified solvent $(375 \mu \mathrm{L})$ and acetone $(184 \mu \mathrm{L})$ (total solvent volume $=559 \mu \mathrm{L})$ at $4{ }^{\circ} \mathrm{C}$ was added $39 \mu \mathrm{L}$ methylglyoxal solution $\left(40 \%\right.$ in $\left.\mathrm{H}_{2} \mathrm{O}\right)$. The reaction was stirred at $4{ }^{\circ} \mathrm{C}$ for $20 \mathrm{~h}$ and purified using FC.

b Determined using chiral stationary phase GC and confirmed using chiral stationary phase HPLC.

c Reaction time was $68 \mathrm{~h}$.

We explored this reaction using a number of catalysts, as shown in Table 1. (S)-Proline $\mathbf{4}$ afforded little or no conversion under preparative conditions at $4{ }^{\circ} \mathrm{C}$ (entries $1-3$ ). Prolinamide 5 proved to be a more efficient catalyst in terms of both yield and enantioselectivity (entry 4). The dipeptide Pro-Leu 7 gave better enantioselectivity than $\mathbf{5}$ at a slightly lower yield (entry 6), while amide $\mathbf{8}$ offered yield and selectivity comparable to that observed for $\mathbf{5}$ (entry 7). Catalyst 6 was not effective for this reaction (entry 5) and the proline derivatives $\mathbf{9}$ and $\mathbf{1 0}$ (entries 8 and 9) offered no obvious advantages compared to catalysts $\mathbf{5}, \mathbf{7}$ or $\mathbf{8}$. Thus, $\mathbf{5}, \mathbf{7}$, and $\mathbf{8}$ all showed promise in this reaction, but we chose to focus our efforts on $\mathbf{5}$ and $\mathbf{7}$ due to the closer resemblance of these catalysts to physiological entities.

We settled on using $20 \mathrm{~mol} \%$ prolinamide $\mathbf{5}$ or Pro-Leu $\mathbf{7}$ as our standard catalyst loading, at a concentration of methylglyoxal $\mathbf{1}$ of 0.4 M. We note that 7 has limited solubility in all solvents explored. Indeed, in all reactions run with catalyst $\mathbf{7}$, the reaction mixture was an inhomogeneous suspension, so the precise catalyst loading when applying $\mathbf{7}$ is unknown.

The results with prolinamide $\mathbf{5}$ are shown in Table 2 and the best results with this catalyst were obtained by running the reaction in neat acetone. Interestingly, both polar protic solvents $\left(\mathrm{H}_{2} \mathrm{O}\right.$ and $i-\mathrm{PrOH}$, entries 8 and 9$)$ and the less polar solvents (toluene and $\mathrm{CH}_{2} \mathrm{Cl}_{2}$, entries 1 and 2) gave poorer enantioselectivity than solvents of moderate polarities ( $\mathrm{MeCN}$ and acetone, entries 3 and 10). The very polar DMSO also gave poor enantioselectivity (entry 7). In all of our reactions, we used commercially available 1, which is a $40 \%$ aqueous solution. Given the poor enantioselectivity observed in protic solvents, we investigated the effect of drying agents on reactions run in $\mathrm{MeCN}$. The addition of $\mathrm{Na}_{2} \mathrm{SO}_{4}$ had no effect on the reaction (entry 4), while the addition of $\mathrm{MgSO}_{4}$ did result in a small increase in enantioselectivity at a modest expense in yield (entry 5). It is possible that the increase in selectivity observed in the presence of $\mathrm{MgSO}_{4}$ is the result of a change in
Table 2

Optimization of conditions for the prolinamide-catalyzed formation of Henze's Ketol $\mathbf{3}^{\text {a }}$<smiles>CC(=O)CC(O)C(C)=O</smiles>

\begin{tabular}{llcll}
\hline Entry & Solvent & Temperature $\left({ }^{\circ} \mathrm{C}\right)$ & Yield $(\%)$ & ee $^{\text {b }}(\%)$ \\
\hline $\mathbf{1}$ & Toluene & 4 & 44 & 32 \\
$\mathbf{2}$ & $\mathrm{CH}_{2} \mathrm{Cl}_{2}$ & 4 & 49 & 56 \\
$\mathbf{3}$ & $\mathrm{CH}_{3} \mathrm{CN}$ & 4 & 66 & 68 \\
$\mathbf{4}^{\mathrm{c}}$ & $\mathrm{CH}_{3} \mathrm{CN}$ & 4 & 66 & 68 \\
$\mathbf{5}^{\mathrm{d}}$ & $\mathrm{CH}_{3} \mathrm{CN}$ & 4 & 52 & 76 \\
$\mathbf{6}$ & $\mathrm{DMF}$ & 4 & $\mathrm{nd}^{\mathrm{e}}$ & 68 \\
$\mathbf{7}$ & $\mathrm{DMSO}$ & 4 & 47 & 38 \\
$\mathbf{8}$ & $\mathrm{H}$ O & 4 & 70 & 0 \\
$\mathbf{9}$ & $i$-PrOH & 4 & 74 & 56 \\
$\mathbf{1 0}$ & Neat & 4 & 76 & 65 \\
$\mathbf{1 1}$ & Neat & -24 & 83 & 71 \\
\hline
\end{tabular}

a Standard conditions: To a stirred solution of the catalyst $(0.05 \mathrm{mmol})$ in the specified solvent $(375 \mu \mathrm{L})$ and acetone $(184 \mu \mathrm{L})($ total solvent volume $=559 \mu \mathrm{L})$ at the specified temperature was added $39 \mu \mathrm{L}$ methylglyoxal solution $\left(40 \%\right.$ in $\left.\mathrm{H}_{2} \mathrm{O}\right)$. The reaction was stirred at the specified temperature for $20 \mathrm{~h}$ and purified using FC.

b Determined using chiral stationary phase GC and confirmed using chiral stationary phase HPLC.

c $\mathrm{Na}_{2} \mathrm{SO}_{4}$ added as drying agent.

d $\mathrm{MgSO}_{4}$ added as drying agent.

e The DMF was not readily separated from the product by FC and given that this solvent offered no obvious advantages in enantioselectivity over others, we did not attempt further purification that would have allowed a yield determination.

mechanism to one involving chelation control by magnesium ion, but in any case, the exclusion of bulk water in the reaction mixture does not have a large effect on the stereoselectivity of the reaction. Lowering the reaction temperature to $-24^{\circ} \mathrm{C}$, using neat acetone, had a small positive effect on both yield and enantioselectivity (cf. entries 10 and 11).

The results with the dipeptide Pro-Leu 7 are presented in Table 3 . With the exception of water (entry 6) this catalyst consistently delivered good enantioselectivities (73-88\% ee) in all solvents tested. On the other hand, the yields were generally lower than those observed with prolinamide 5. $\mathrm{CH}_{2} \mathrm{Cl}_{2}$ offered excellent enantioselectivity, but with very poor conversion, probably as a result of the low solubility of $\mathbf{7}$ in this solvent. Of the solvents examined, neat acetone and EtOH emerged as the solvents of choice for catalyst $\mathbf{7}$, with acetone giving the highest enantioselectivity (entry 1) and EtOH providing respectable selectivity at a higher yield (entry 5).

Table 3

Optimization of conditions for the Pro-Leu-catalyzed formation of Henze's Ketol $\mathbf{3}^{\mathrm{a}}$

\begin{tabular}{lllll}
\hline Entry & Solvent & Reaction time $(\mathrm{h})$ & Yield $(\%)$ & $\mathrm{ee}^{\mathrm{b}}(\%)$ \\
\hline $\mathbf{1}$ & Neat & 68 & 55 & 88 \\
$\mathbf{2}$ & $i-\mathrm{PrOH}$ & 21 & 16 & 82 \\
$\mathbf{3}$ & $i-\mathrm{PrOH}$ & 72 & 30 & 83 \\
$\mathbf{4}$ & $\mathrm{DMF}$ & 21 & 51 & 81 \\
$\mathbf{5}$ & $\mathrm{EtOH}$ & 70 & 77 & 81 \\
$\mathbf{6}$ & $\mathrm{H}_{2} \mathrm{O}$ & 120 & 27 & 45 \\
$\mathbf{7}$ & $\mathrm{CH}_{2} \mathrm{Cl}_{2}$ & 20 & $<5$ & 88 \\
$\mathbf{8}$ & $\mathrm{DMSO}$ & 21 & 49 & 73 \\
\hline
\end{tabular}

a Standard conditions: To a stirred solution of the catalyst $(0.05 \mathrm{mmol})$ in the specified solvent $(375 \mu \mathrm{L})$ and acetone $(184 \mu \mathrm{L})$ (total solvent volume $=559 \mu \mathrm{L})$ at the specified temperature was added $39 \mu \mathrm{L}$ methylglyoxal solution $\left(40 \%\right.$ in $\left.\mathrm{H}_{2} \mathrm{O}\right)$. The reaction was stirred at $4{ }^{\circ} \mathrm{C}$ for the specified time period and purified using flash chromatography.

b Determined using chiral stationary phase GC and confirmed using chiral stationary phase HPLC. 
Table 4

Reaction of acetone $\mathbf{2}$ or acetoacetate $\mathbf{1 1}$ with methylglyoxal $\mathbf{1}^{\mathrm{a}, \mathrm{b}}$

$$
\text { (12.5 mM) }
$$

\begin{tabular}{lllll}
\hline Entry & {$[\mathbf{1}](\mu \mathrm{M})$} & Amino acid & Additive & {$[\mathbf{3}](\mu \mathrm{M})$} \\
\hline $\mathbf{1}^{\mathrm{c}}$ & 375 & None & - & $1.78 \pm 0.14$ \\
$\mathbf{2}^{\mathrm{c}}$ & 375 & (S)-Proline & - & $4.66 \pm 0.20$ \\
$\mathbf{3}^{\mathrm{c}}$ & 375 & aa-mix & - & $2.81 \pm 0.26$ \\
$\mathbf{4}^{\mathrm{c}}$ & 375 & aa-mix & Red-glu $(1 \mathrm{mM})$ & $1.22 \pm 0.06$ \\
$\mathbf{5}^{\mathrm{c}}$ & 375 & aa-mix & Red-glu $(5 \mathrm{mM})$ & $0.24 \pm 0.03$ \\
$\mathbf{6}^{\mathrm{c}}$ & 375 & aa-mix & Red-glu $(1 \mathrm{mM})$ HSA $(0.3 \mathrm{mM})$ & $1.03 \pm 0.10$ \\
$\mathbf{7}^{\mathrm{d}}$ & 63 & aa-mix & Red-glu $(1 \mathrm{mM})$ HSA $(0.3 \mathrm{mM})$ & $2.20 \pm 0.07$ \\
\hline
\end{tabular}

a Reactions were initiated by adding the nucleophile to a pre-equilibrated mixture of all other components at $37^{\circ} \mathrm{C}$. Results are an average of two experiments. aa-mix $=a$ mixture of 25 amino acids present at $>3 \mu \mathrm{M}$ concentration in human plasma at the levels found in healthy persons (see Ref. 15). HSA = Human Serum Albumin. Red-glu = reduced glutathione.

b Total amino acid concentration is $2.4 \mathrm{mM}$ (entry 2) and $2.7 \mathrm{mM}$ (entries 3-7).

c Acetone is used as aldol-donor nucleophile.

d Acetoacetate is used as aldol-donor nucleophile.

We also investigated the amenability of the reaction to scaleup. We first ran a gram-scale reaction with the fully soluble prolinamide $\mathbf{5}$ in neat acetone at $-24^{\circ} \mathrm{C}$. Using just $10 \mathrm{~mol} \% \mathbf{5}$, we isolated $1.6 \mathrm{~g}$ of Henze's ketol $\mathbf{3}$ in 93\% yield and with 74\% ee-both values even marginally better than our results on the milligram scale (Table 2, entry 11 ). On the other hand, scaling-up the reaction using the largely insoluble Pro-Leu 7 was less successful. The gramscale reaction using $10 \mathrm{~mol} \% \mathbf{7}$ in neat acetone at $4{ }^{\circ} \mathrm{C}$ afforded 3 with enantioselectivity ( $87 \%$ ee) comparable to that of the milligram-scale reaction (Table 3 , entry 1 ), but at a significantly lower yield (37\%). Thus, catalyst $\mathbf{5}$ gives the best overall results at the gram-scale, and the synthesis of $\mathbf{3}$ with this catalyst represents a marked improvement over the racemic, two-step literature preparation of $\mathbf{3}$ from methylglyoxal $\mathbf{1}$ and ethyl acetoacetate.

Due to the importance of methylglyoxal $\mathbf{1}$ and acetone $\mathbf{2}$ as endogeneous compounds and since the aldol reaction can indeed be catalyzed by physiologically relevant amino acids and small peptides, we turned our attention to the possible biochemical significance of the reaction. We began by exploring the reaction of acetone $\mathbf{2}$ with methylglyoxal $\mathbf{1}$ under conditions designed to approximate those found in vivo (Eq. 1). Using LC-MS/MS to detect and quantify Henze's ketol $\mathbf{3}$ formed with low concentrations of the reactants, we gradually increased the complexity of the experimental set-up (Table 4). When $375 \mu \mathrm{M} 1$ and $12.5 \mathrm{mM} 2$ were incubated at $37{ }^{\circ} \mathrm{C}$ and $\mathrm{pH} 7.3$ for $24 \mathrm{~h}$, micromolar concentrations of $\mathbf{3}$ were detected. (S)-Proline $\mathbf{4}$ (entry 2 ) was found to accelerate the aldol reaction, under these buffered conditions, by a factor of roughly 2.6 over the background reaction (entry 1 ). Next, we exchanged 4 for the 25 amino acids present at $>3 \mu \mathrm{M}$ concentration in human plasma at the levels found in healthy persons (entry 3). ${ }^{15}$ Although this environment presents a multitude of reversible and irreversible binding possibilities for $\mathbf{1}$, the aldol reaction still proceeds and is even accelerated over the background reaction. Thiols are known to bind strongly to $1\left(K_{\mathrm{D}}=1.4 \times 10^{-5}\right) ;{ }^{16}$ however, the dynamics of this process still permit $\mathbf{1}$ to dissociate and undergo the aldol reaction. As shown in entries 4 and 5, physiological concentrations of red-glutathione do not retard the reaction, and even when $0.29 \mathrm{mM}$ human serum albumin (HSA) ${ }^{17}$ was included (entry 6), $1.03 \mu \mathrm{M}$ of Henze's ketol 3 was observed after
24 h. We have observed that acetoacetate 11, a biological precursor to acetone during ketosis, turned out to be more reactive than acetone $\mathbf{2}$ under more demanding conditions in terms of reactant concentrations. As shown in entry $7,3.5 \%$ of $\mathbf{1}$, when present at just $63 \mu \mathrm{M}$, was converted into 3 in the presence of $6.3 \mathrm{mM}$ of $\mathbf{1 1}$. These results demonstrate that $\mathbf{1}$ does react readily with ketones under conditions that simulate human plasma.

Finally, we explored the preparative-scale reaction of freshly prepared acetoacetate $\mathbf{1 1}$ with methylglyoxal $\mathbf{1}$ under aqueous conditions similar to those reported ${ }^{12}$ in the established two-step synthesis of Henze's ketol 3, but with the addition of $30 \mathrm{~mol} \%$ prolinamide $\mathbf{5}$ (Eq 2). Under these organocatalytic conditions, $\mathbf{3}$ is formed in $81 \%$ yield, but as a racemate. For comparison, the aldol reaction of $\mathbf{1}$ with acetone $\mathbf{2}$ under the same conditions afforded 3 in 25\% yield and with $14 \%$ ee. It seems that the aldol reaction between $\mathbf{1}$ and $\mathbf{1 1}$ under these conditions is so facile that it is not influenced by the organocatalyst, which is consistent with our observations of the reactivity of $\mathbf{1 1}$ under the simulated physiological conditions (Table 4, entry 7).

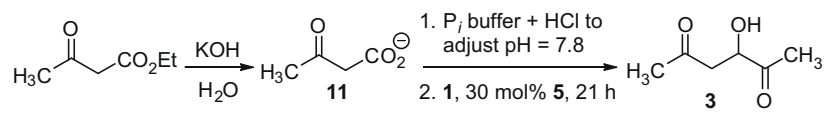

We have shown that methylglyoxal $\mathbf{1}$ is an efficient aldol acceptor and that preparative organocatalytic reactions can be carried out with the commercially available solution of $\mathbf{1}$ and acetone $\mathbf{2}$ with high yields and enantioselectivities. Furthermore, the aldol product 3 is also readily formed under simulated in vivo conditions. Although the rate acceleration here is modest, our results encourage further investigations into the role organocatalysis may play in human biochemistry and how it may impact the turn-over of methylglyoxal during ketosis. Further studies are aimed at identifying these aldol products in vivo, as well as establishing if the reactions are enantioselective under conditions found in vivo.

\section{Acknowledgements}

This work was made possible by support from Danish National Research Foundation, OChem School and Carlsberg Foundation.

\section{Supplementary data}

Supplementary data associated with this article can be found, in the online version, at doi:10.1016/j.bmcl.2009.03.128.

\section{References and notes}

1. Chem. Rev. 2007, 107. special issue on organocatalysis

2. List, B.; Lerner, R. A.; Barbas, C. F., III J. Am. Chem. Soc. 2000, 122, 2395.

3. See example: Carpenter, J.; Northrup, A. B.; Chug, M.; Wiener, J. J. M.; Kim, S.-G.; MacMillan, D. W. C. Angew. Chem., Int. Ed. 2008, 47, 3568.

4. Houk, K. N.; Cheong, P. H.-Y. Nature 2008, 455, 309. and references herein.

5. Dickerson, T. J.; Janda, K. D. J. Am. Chem. Soc. 2002, 124, 3220.

6. (a) Ramachary, D. B.; Chowdari, N. S.; Barbas, C. F., III Angew. Chem., Int. Ed. 2003, 42, 4233; (b) Barbas, C. F., III Angew. Chem., Int. Ed. 2008, 47, 42.

7. (a) Thornalley, P. J. Ann. N.Y. Acad. Sci. 2005, 1043, 111; (b) Nemet, I.; VargaDefterdarović, L.; Turk, Z. Mol. Nutr. Food Res. 2006, 50, 1105.

8. Chaplen, F. W. R. Cytotechnology 1998, 26, 173.

9. Chaplen, F. W. R.; Fahl, W. E.; Cameron, D. C. Proc. Natl. Acad. Sci. U.S.A. 1998, 95, 5533.

10. Kashket, S.; Maiden, M. F. J.; Haffajee, A. D.; Kashket, E. R. J. Clin. Periodontol 2003, 30, 364 .

11. (a) Felby, S.; Nielsen, E.; Thomsen, J. L. Forensic Sci. Med. Pathol. 2008, 4, 100; (b) Umpierrez, G. E.; DiGirolamo, M.; Tuvlin, J. A.; Isaacs, S. D.; Bhoola, S. M.; Kokko, J. P. J. Crit. Care 2000, 15, 52.

12. (a) Henze, M.; Müller, R. Z. Physiol. Chem. 1933, 214, 281; (b) Schechter, M. S.; Green, N.; LaForge, F. B. J. Am. Chem. Soc. 1949, 71, 3165.

13. Holmes, F. L. Hans Krebs-The Formation of a Scientific Life 1900-1933; Oxford University Press: Oxford, 1991. p 245. 
14. (a) Li, Y.; Shi, Y.-P. Pharmazie 2007, 62, 714; (b) Fang, J.-M.; Wang, K.-C.; Cheng, Y.-S. J. Chin. Chem. Soc. 1991, 38, 297.

15. Cynober, L. A. Nutrition 2002, 18, 761.

16. Lo, T. W. C.; Westwood, M. E.; McLellan, A. C.; Selwood, T.; Thornalley, P. J. J. Biol. Chem. 1994, 269, 32299.
17. $0.29 \mathrm{mM}$ of HSA contributes $290 \mu \mathrm{M}$ of cysteine, up to $11,600 \mu \mathrm{M}$ lysine ( 40 out of 59 residues), and up to $6040 \mu \mathrm{M}$ arginine (21 out of 23 residues) that can be expected to bind 1 reversibly and irreversibly, see: Westwood, M. E.; McLellan, A. C.; Thornalley, P. J. J. Biol. Chem. 1994, 269, 32293. 